\title{
LTCC-technology for Producing Hexaferrites
}

\author{
D.N. Chitanov ${ }^{1}$, V.G. Kostishyn ${ }^{1, *}$, L.V. Kozhitov¹, P.A. Ryapolov², A.Yu. Adamtsov ${ }^{1}$ \\ ${ }^{1}$ National University of Science and Technology "MISiS", 4, Leninsky prosp., 119049, Moscow, Russia \\ 2 Southwest State University, 94, 50 let Octyabrya st., 305040 Kursk, Russian
}

(Received 17 May 2016; published online 03 October 2016)

\begin{abstract}
In the review examined the possibility of using LTCC-technology for obtaining hexaferrites as reaction additives glasses $\mathrm{Bi}_{2} \mathrm{O}_{3}-\mathrm{B}_{2} \mathrm{O}_{3}-\mathrm{SiO}_{2}-\mathrm{ZnO}(\mathrm{BBSZ})$ and $\mathrm{BaCu}\left(\mathrm{B}_{2} \mathrm{O}_{5}\right)(\mathrm{BCB})$ to reduce the sintering temperature. It is shown that compatibility between hexaferrites with the addition BBSZ, BCB and silver paste, which is a key requirement in the manufacturing process LTCC-components. Considered the possibility of co-sintering of ferrites and dielectric tape composites. It was established that for the realization of defectfree LTCC-composite need to control the shrinkage of the two tapes. In this connection becomes an important concept of zero shrinkage and limiting sintering.
\end{abstract}

Keywords: Hexagonal ferrite, LTCC-technology, Microstructure, Reaction glass, Density

DOI: $10.21272 /$ jnep.8(3).03016

PACS numbers: $75.50 . \mathrm{Gg}, 75.75 .+\mathrm{a}$

\section{INTRODUCTION}

General technology of production LTCC-devices is as follows. Raw ceramics rolled, molded and cut into a fixed-size sheets. Further, selected the required number of sheets a given thickness with a required value of the dielectric constant.

In the sheets break the required number of holes for interlayer conductive and heat-conducting passages, and performed additional mechanical processing sheets, for example, the edges specially shaped according to the product design. Further, special holes are filled conductive composition, and to the surface is applied conductive pattern topology.

Thereafter, it is doing assembly of the multilayer structure of the substrate with careful combining multilayer transitive apertures, and as a binder layer is used a crystallized glass. Then, to the upper and lower layers applied a protective coating, and the entire structure is subjected to heat treatment, which occurs as a result of its sintering.

Thereafter, it is performing the mechanical processing the outer layers of the structure (grinding), in which the protective coating is removed, and the surface becomes flat. Next, the cleaned surface of the upper and lower layers applied conductive pattern and the resistive elements wherein for resistors of large and small resistances use different resistive ink with the corresponding resistivity.

After the final firing of the outer layers is performed laser trimming resistors ratings and the substrate becomes completely prepared for surface mounting hinged components.

With the growing demand for portable electronic devices require further miniaturization and weight reduction. Integration of induction coils, capacitors and resistors in one small monolithic chip provides better performance and saves space with a higher level of integration on a printed circuit. Multicompound multilayer co-fired materials from soft magnetic material with high magnetic permeability and a dielectric mate- rial with a high dielectric constant at high frequencies, provide co-fired capacitor and inductor coil, and are one of the most interesting, but sophisticated approaches [1]. Mismatch compaction kinetics, chemical reactions and mismatch thermal expansion between the layers can generate undesirable defects such as delamination, crack, collapse and reduce performance secondary phase [2-4]. Thus, the development of low-temperature processes usually demonstrates significant changes in the properties of materials above $200 \mathrm{MHz}$ because Snoek limit [5]. Maximum factor quality-frequency (QxE) in chips inductor of a nonmagnetic material above $500 \mathrm{MHz}$. However, the quality factor for frequencies of about 200-300 $\mathrm{MHz}$ are significantly lower than at higher frequencies [6]. Since the chip inductor was prepared by winding a wire around a core of nonmagnetic material, it is necessary to have a greater number of turns of the coil winding to obtain the desired inductance, thereby limiting miniaturization. Thus, it is desirable to develop a low-temperature burned (below $950{ }^{\circ} \mathrm{C}$ ) magnetic material having a higher quality factor than nonmagnetic materials at $200-300 \mathrm{MHz}$ for use in the manufacture multilayer high frequency chip inductor. Ferrites with a hexagonal structure show higher dispersion of frequencies than NiCuZn ferrites used in microwave applications [7, 8]. Among these ferrites $\mathrm{BaFe}_{12} \mathrm{O}_{19}$ and $\mathrm{SrFe}_{12} \mathrm{O}_{19}$ M-type ferrites having good magnetic properties such as permeability and quality factor above $200 \mathrm{MHz}$ [9].

\section{ADDITIVES TO REDUCE THE SINTERING TEMPERATURE}

Development of LTCC-magnetic has trend to use a small amount of additives and glass-ceramics systems including softening glasses and magnetic ceramics with a high melting point. Typical additive for low temperature sintered hexaferrites prepared by a low value mixing with the oxide $-\mathrm{Bi}_{2} \mathrm{O}_{3}$. It is also possible to add lithium borosilicate glass or $\mathrm{B}_{2} \mathrm{O}_{3}-\mathrm{Sb}_{2} \mathrm{O}_{3}$. The main problem with low temperature fired polycrystalline

\footnotetext{
*drvgkostishyn@mail.ru
} 
magnetic phases like $\mathrm{BaFe}_{12} \mathrm{O}_{19}$ - high porosity. Due to the high content of nonmagnetic phases (> 10 vol. \%), such as glass or a pores phase permeability sharply reduced. Reaction glasses $\mathrm{Bi}_{2} \mathrm{O}_{3}-\mathrm{B}_{2} \mathrm{O}_{3}-\mathrm{SiO}_{2}-\mathrm{ZnO}$ (BBSZ) partially solve this problem, they used to lower the sintering temperature hexaferrites, but magnetic properties are not satisfactory. Thus, there is an additional necessity to reduce the sintering temperature and optimize magnetic properties of barium ferrite to satisfy requirements of LTCC multilayer devices.

Glass $\mathrm{BaCu}\left(\mathrm{B}_{2} \mathrm{O}_{5}\right)(\mathrm{BCB})$ may be selected as an additive that reduces sintering. It melts and acts as a flux at $850^{\circ} \mathrm{C}$. The coercive force can be reduced preserving relatively high magnetization saturation of barium ferrite, if Fe (III) ions simultaneously displace divalent and tetravalent cations.

In the work [10] was shown that the first traces $\mathrm{BaFe}_{12} \mathrm{O}_{19}$ observed at temperature about $1000{ }^{\circ} \mathrm{C}$, but clean hexaferrite phase obtained at $1200{ }^{\circ} \mathrm{C}$ (Fig. 1 [10]). Thus, this temperature can be used to calcine the mixed oxide precursor.

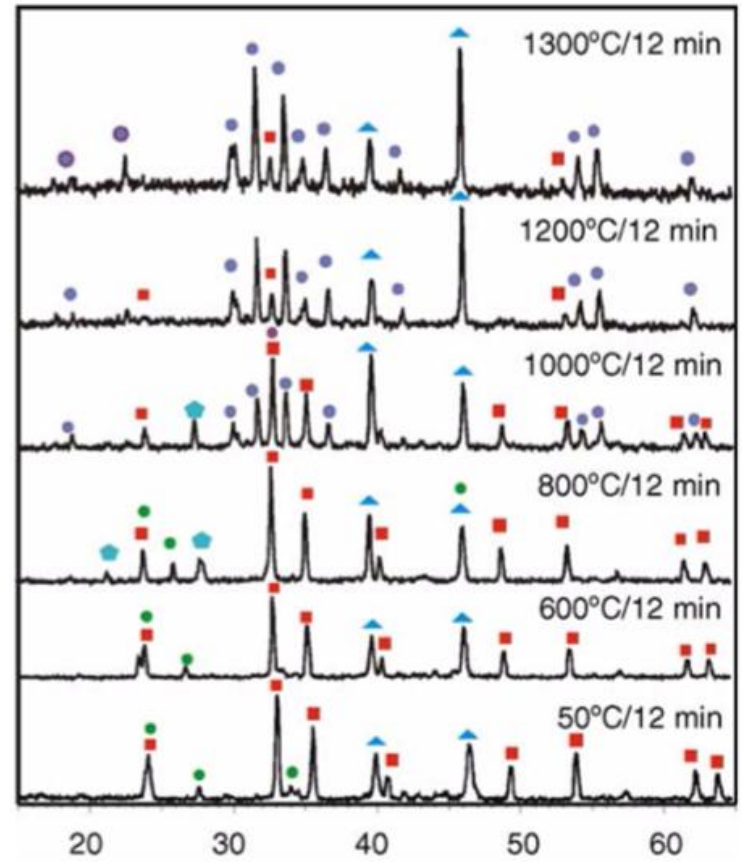

Fig. 1. - High temperature X-ray thermally processed mixture of $\mathrm{BaCO}_{3}$ and $\mathrm{Fe}_{2} \mathrm{O}_{3}$

Behavior shrinkage $\mathrm{Ba}(\mathrm{Co}, \mathrm{Ti})_{x} \mathrm{Fe}_{12-2 x} \mathrm{O}_{19} \quad(x=1,2)$ magnetic ceramics samples with content and without content BBSZ-glasses during thermal treatment are shown in the work [1]. The relationship between linear shrinkage levels of shrinkage and heat treatment temperature are shown in Fig. 2 [1]. Magnetic ceramics samples with the addition of BBSZ-glasses had lower starting temperature shrinkage indicates the initial sintering stage than the sample without glasses content. Sample without the addition of glasses started to shrink at a temperature of $1250^{\circ} \mathrm{C}$. Sample 4 wt. \%. BBSZ-glasses began to shrink at a temperature of $900^{\circ} \mathrm{C}$. By increasing the glasses content, starting temperature of shrinkage is reduced further. When the samples had a content BBSZ-glass is higher than 12 wt. \% starting temperature of shrinkage was lower than $850^{\circ} \mathrm{C}$. The temperature of the maximum level of shrinkage, as the estimated temperature sintering of powders was $970,950,930$ and $925^{\circ} \mathrm{C}$ for samples 4,8 , 12 and 16 wt. \% content of BBSZ-glass, respectively.

The highest relative density was achieved with 12 wt. $\%$ addition of glass. After sintering at $1050{ }^{\circ} \mathrm{C}$ and $950{ }^{\circ} \mathrm{C}$ it was $97 \%$ and higher $94 \%$, respectively. Further increase in the content of glass is mainly a relative density decreases. This may be due to the high content of the liquid phase and the formation of closed pores.

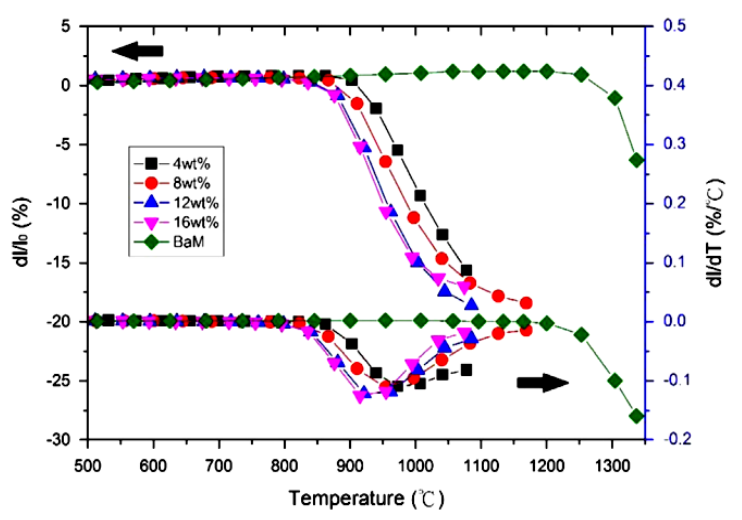

Fig. 2 - Linear shrinkage and shrinkage level $\mathrm{Ba}(\mathrm{Co}, \mathrm{Ti})_{x} \mathrm{Fe}_{12}$ ${ }_{2 x} \mathrm{O}_{19}$ magnetic ceramics samples during thermal treatment

Detailed values shrinkage and porosity depending on the number of BBSZ- glass for composition $\mathrm{BaFe}_{12} \mathrm{O}_{19}$ given in Table 1 [10].

Table 1 - Effect of amount of reactive glass on open porosity and shrinkage

\begin{tabular}{lcc}
\hline Glass (vol\%) & Shrinkage (\%) & Porosity (vol\%) \\
\hline 0 & 3 & $>50$ \\
3 & 17 & 15 \\
5 & 19 & 2.3 \\
7 & 22 & 0.8 \\
\hline
\end{tabular}

These results indicate that the addition BBSZ-glass may contribute significantly to compacted magnetic ceramics.

Using 1-4 wt. \% BCB additives hexaferrite composition $\mathrm{Ba}(\mathrm{CoTi})_{0.9} \mathrm{Fe}_{11} \mathrm{O}_{19}$ in the work $[11,12]$, it was found the optimum content of additive for compacting the ferrite particle The bulk densities of $\mathrm{Ba}(\mathrm{CoTi})_{0.9} \mathrm{Fe}_{11} \mathrm{O}_{19}$ with the addition of $1-4$ wt. \% BCB were subjected co-fired at various temperatures, as shown in Figure 3 [11]. It can be seen that the maximum density is increased from $4.6 \mathrm{~g} / \mathrm{cm}^{3}$ ( $86 \%$ of theoretical density) to $4.9 \mathrm{~g} / \mathrm{cm}^{3}$ (94\% of theoretical density) at BSB varying from 1 to 4 wt. \%. Obviously, the maximum density increased with increasing content of $\mathrm{BCB}$, and reaches a maximum when the sample $3 \mathrm{wt}$. $\%$ BCB sintered at $900{ }^{\circ} \mathrm{C}$. It is considered that during sintering of ceramics BCB form a liquid phase at $850{ }^{\circ} \mathrm{C}$ and act as a flux [13]. The liquid phase reacts with the barium ferrite, contributing to the promotion of mass and diffusion in the ferrite, thereby facilitating compaction [14]. On the other hand, it can also be determined that the density does not always increase with increasing temperature. It is considered that the liquid phase is vaporized and passes some possible re- 
actions at higher temperature [14]. These results show that the addition of $3 \mathrm{wt}$ \% BSB sufficient to lower the sintering temperature of the barium ferrite to $900{ }^{\circ} \mathrm{C}$.

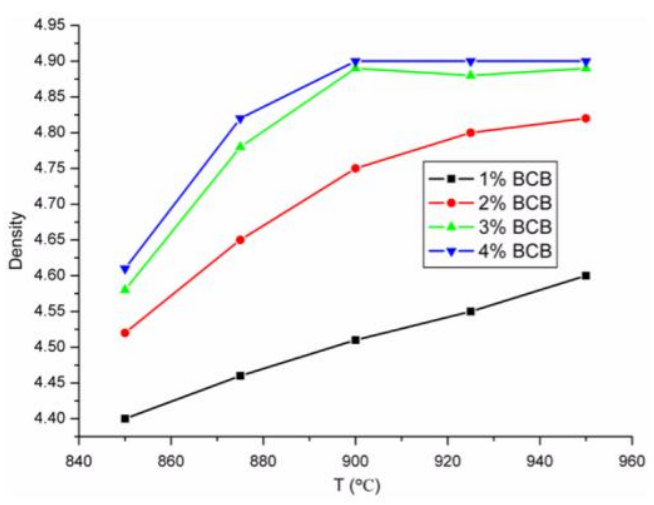

Fig. 3 - Bulk densities $\mathrm{Ba}(\mathrm{CoTi})_{0.9} \mathrm{Fe}_{11} \mathrm{O}_{19}$ with the addition of 1-4 wt. \% BSB sintered at the different temperatures

Dosage glass reaction plays an important role in the ferrite crystallization. In the mechanism of formation of barium ferrite are the two following reactions [15]:

$$
\begin{gathered}
\mathrm{BaCO}_{3}+\mathrm{Fe}_{2} \mathrm{O}_{3}=\mathrm{BaFe}_{2} \mathrm{O}_{4}+\mathrm{CO}_{2} \\
\mathrm{BaFe}_{2} \mathrm{O}_{4}+5 \mathrm{Fe}_{2} \mathrm{O}_{3}=\mathrm{BaFe}_{12} \mathrm{O}_{19}
\end{gathered}
$$

In other studies [16, 17], intermediate compounds such as $\mathrm{Fe}_{2} \mathrm{O}_{3}$ and $\mathrm{BaFe}_{2} \mathrm{O}_{4}$ often detected. For example, Young et al. found $\mathrm{Fe}_{2} \mathrm{O}_{3}$ in the manufacture of pure barium ferrite [18] and Liu et al. reported the excess barium by forming $\mathrm{BaFe}_{2} \mathrm{O}_{4}$ [19]. In the results of the work [12] was not $\mathrm{BaFe}_{2} \mathrm{O}_{4}$. Thus, it can be concluded that the BCB is completely transformed into the liquid phase. Furthermore, clearly it observed that a$\mathrm{Fe}_{2} \mathrm{O}_{3}$ and $\mathrm{BaFe}_{12} \mathrm{O}_{19}$ appear simultaneously when BCB content below 3 wt. \%. However, $\mathrm{Fe}_{2} \mathrm{O}_{3}$ phase disappeared and single phase barium ferrite M-type was formed at the enlarged $\mathrm{BCB}$ content to $3 \mathrm{wt} . \%$. It is considered that the formation of pure phase $\mathrm{BaFe}_{12} \mathrm{O}_{19}$ accelerated by the BCB liquid phase. On the other hand, although $\mathrm{BCB}$ was added to BaM, no peak of $\mathrm{BCB}$ second phase was not detected in the radiograph. This reason is that $\mathrm{BCB}$ exist as a liquid phase and an amorphous phase retained upon cooling [13].

\section{COMPATIBILITY HEXAFERRITES WITH SILVER ELECTRODES}

Silver (Ag), is generally used as the internal metal electrode in LTCC-multilayer devices due to its low losses and low electrical resistance at high frequencies, but the melting point of $\mathrm{Ag}=961^{\circ} \mathrm{C}$, i.e. is small. Therefore, for the manufacture LTCC-multilayer devices, it is important to use ferrites having a sintering temperature below $961{ }^{\circ} \mathrm{C}$ to prevent diffusion of $\mathrm{Ag}$ and shrinkage $[10,20]$.

Thus during manufacture LTCC-components necessary compatibility between $\mathrm{BaFe}_{12} \mathrm{O}_{19}$ with the additive BBSZ and silver paste. Should not be diffusion and no leakages between the paste and composite. The results of work [10] and Figure 4 show the SEM-pictures between the glass-ceramics composite and silver paste. By analogy with the image shows the EDX-lines of the spectrum scanning of the same interface. Leakages between glass-ferrite composite and the paste after sintering is not observed. EDX spectra show a sharp transition between the $\mathrm{Ag}$ and paste on the one hand, and $\mathrm{Ba}$ and $\mathrm{Fe}$ tapes on the other hand. This means that there is no diffusion between the paste and tape. Signal Si, Bi and Zn, coming from BBSZ-glass, added in very small quantities and are not essential for interpretation.
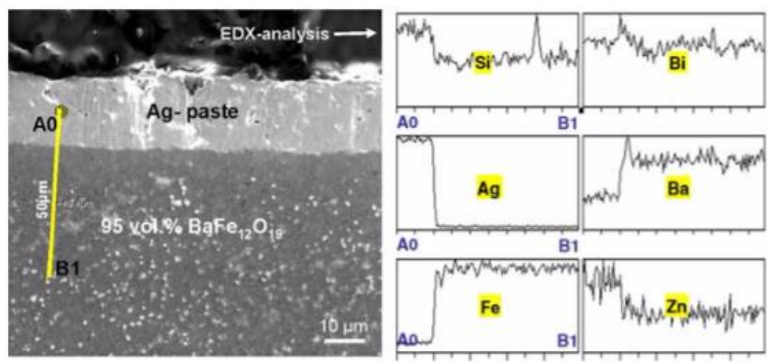

Fig. 4 - Compatibility LTCC- glass-ceramics composite and Ag-paste

However, due to different kinetics of sintering between the ferrite and silver in the samples often observed cracks, delamination and collapse. However, these defects were not found in the work [11] by using $\mathrm{Ba}(\mathrm{Co}, \mathrm{Ti})_{x} \mathrm{Fe}_{12-2 x} \mathrm{O}_{19}$ containing BCB. Silver paste distributed in the central region of the conductor, does not diffuse into the ferritic region, as shown in figure 5 . This means that the barium ferrite good co-fired with silver paste.

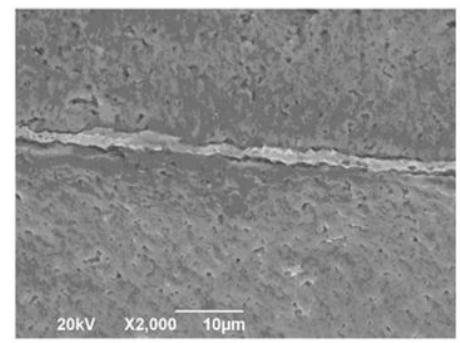

Fig. 5 - SEM-image of barium ferrite with the silver paste, together sintered at $900{ }^{\circ} \mathrm{C}$

At the same additive $\mathrm{BCB}$, but for composition $\mathrm{BaFe}_{12} \mathrm{O}_{19}$ at co-sintering with silver in the work [12] shown positive results. Figure 6 shows that the ferrite layer and layer of the electrode $\mathrm{Ag}$ - compatible and have almost no cracks, delamination and convexity at the boundary between them.

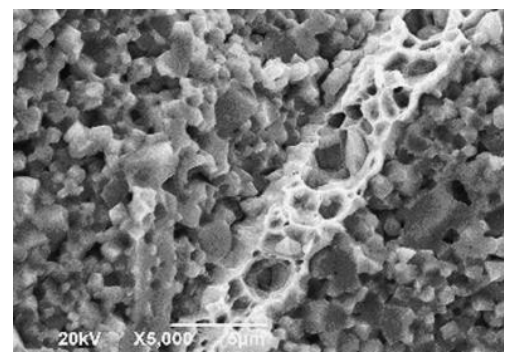

Fig. 6 - SEM result of 3 wt. \% ceramics additives $\mathrm{BaCu}\left(\mathrm{B}_{2} \mathrm{O}_{5}\right)$ to BaM with $\mathrm{Ag}$ electrode co-sintered at $900{ }^{\circ} \mathrm{C}$

Thus, all presented results of studies various com- 
positions hexaferrites containing various additives, to reduce the sintering temperature, give a positive result in co-sintering hexaferrites with silver. It is proved that $\mathrm{Ag}$ does not diffuse into the ferritic region, and extends in a central region of the conductor.

\section{CO-SINTERING OF FERRITE AND DIELEC- TRIC TAPES COMPOSITES}

The potential of the miniaturization devices of LTCC will dramatically improve if it can be integrate the inductor directly into the multi-layer structure, cosintering ferrite tapes in combination with dielectric tapes. In [21] described a commercial dielectric LTCCtape and a newly developed ferrite tape based on $\mathrm{BaFe}_{12} \mathrm{O}_{19}$. For the production of composite structures of these two types tapes according to LTCC technology, ferrite tape should be compacted (sintered) at the temperature about $900^{\circ} \mathrm{C}$. Characteristic tapes includes the study of the behavior of the structure of tapes and shrink by measuring the density, thermogravimetry, thermomechanical analysis, optical dilatometry and microstructure research. By combining the various tapes can be generated behavior of bounding sintering. The resulting defects can be associated with stressful events during the cycles of sintering and cooling.

Integration magnetic properties into existing dielectric LTCC structure would have a significant impact on the miniaturization and the possibility of using LTCC devices in the field of communication and automotive technology. Converters, antennas and circulators - only some of many possible passive devices that may be realized by using ferrite tape. The circulator is composed of three separate devices and allows the RF waves occur between any two adjacent ports, which are limited only in one direction. It contains three transition lines, which are located between two layers of ferrite material. On the other hand ferrite - a non-ferromagnetic substrate, then magnet and non-ferromagnetic pole piece, which protects the device from external magnetic fields. Such circulators may find application in UMTS mobile phones.

In the work [21] was used hexaferrite M-type $\mathrm{BaFe}_{12} \mathrm{O}_{19}$, which has a big advantage - a constant permeability over a wide frequency range. Permeability values spinel ferrites above, but rapidly decrease in the frequency range near $\mathrm{MHz}$. To integrate the ferrite tape should be fired together with the dielectric tape. To implement defect-free composite LTCC necessary to control the shrinkage of the two tapes. Therefore, it is an important concept of zero-shrinkage and sintering restricting [22, 23]. One concept is based on limiting the temporal layers that are laminated on both sides of the multilayer structure. The frictional force between the LTCC layer and the non-sintering temporary layer suppresses shrinkage in the plane. In the work [24] the shrinkage in the plane of the ferrite tape was reduced using a dielectric tape which is compacted in the other temperature range as opposed to the ferrite tape. The dielectric tape should be compacted at low temperatures when it is limited to non-caking ferrite tape. At higher temperatures, the ferrite tape is compacted, but the shrinkage is already hampered by the dense dielectric tape. Thus, sintering is implemented self-limiting because each tape is limiting layer to another.

Cracks, debonding, and other defects observed in multilayer composites due mismatch stresses to different sintering stages $[25,26]$. They can be caused by different rates compaction of individual layers during sintering or mismatched coefficients of thermal expansion during cooling. Thus, a layer with a high coefficient of thermal expansion is under stretching stress and is most susceptible to the formation of cracks.

To reduce the exposure time requires a temperature higher than $900{ }^{\circ} \mathrm{C}$, it is not valid for co-sintering with metal pastes. Using the sintering temperature of $950{ }^{\circ} \mathrm{C}$ for $3 \mathrm{~h}$ instead of $900^{\circ} \mathrm{C}$ for $5 \mathrm{~h}$, the porosity decreases from 6,0 to 1,7 vol. \% [21]. From these results, it is suggested that the high concentration of the binder is not distributed uniformly over the height of the tape leads to the bulge during the binder burnout.

Since intervals sintering dielectric and ferrite films overlap between 760 and $840{ }^{\circ} \mathrm{C}$, one can not expect absolute zero shrinkage composite. However, restricting the sintering was clear achieved (Fig. 7) [21]. The limited resolution of the optical dilatometer $80 \mu \mathrm{m} /$ pixel (equivalent to $\pm 0,3 \%$, depending on the sample size), and low shrinkage values lead to increase scattering data (Fig. 7). In the range of $700-760{ }^{\circ} \mathrm{C}$ compaction dielectric tape suppressed not sintered ferrite tape. Various speed of compaction may cause low shrinkage value of $1.5 \%$ between 760 and $840{ }^{\circ} \mathrm{C}$, although both single tape compacted within this temperature range. At temperatures above $840^{\circ} \mathrm{C}$ ferrite shrinkage is constrained not sintered dielectric tape. When the holding time of $5 \mathrm{~h}$ at $900{ }^{\circ} \mathrm{C}$ shrinkage observed mainly in thickness. The total shrinkage in the plane was $3.25 \%$ for the casting direction, of $2.97 \%$ for the transverse direction, and $33.1 \%$ in the $\mathrm{Z}$ axis direction, due to the shrinkage inhibited in the plane.

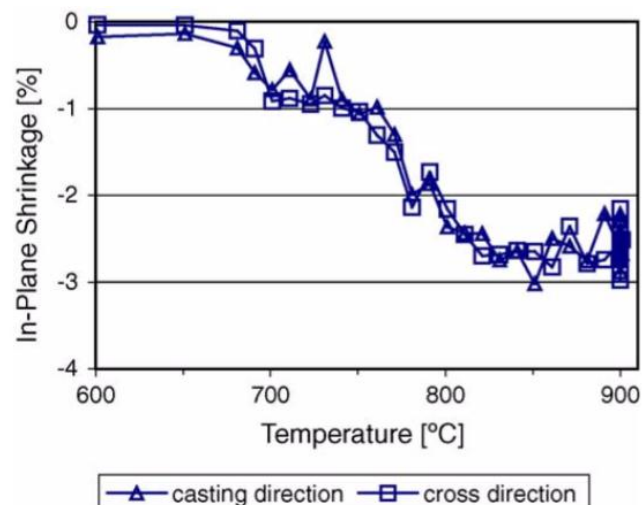

Fig. 7 - Limited shrinkage in the plane symmetrical dielectric and ferrite composite

Various speed of compaction generate mismatch stress sintering; tensile stress in the plane decreases driving force of compaction and is one of the reasons for the origin of the defect. Typical defects observed are shown in Figure 8.

The tendency in modern high-frequency (HF) applications, consists in reducing the size, increasing the packing density and enhance functionality requires substrates to enable embedded passive functions [27]. Along with the high-frequency laminates [28, 29] and 
passive integration in the high-resistivity silicon [3034], a low-temperature co-fired ceramics (LTCC) is an established technology for the realization of highly integrated modules for mobile devices [35, 36].
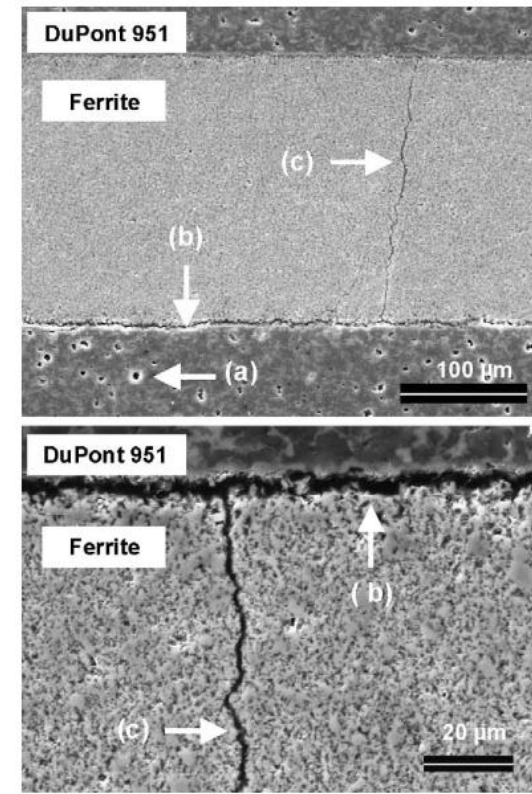

Fig. 8-Defects in the sintered composite: (a) cavitation in DuPont layer, (b) divisive crack and (c) channel crack in ferrite layer

New ceramic materials based hexaferrites with a low temperature firing must be compatible firing properties, dielectric, magnetic and thermomechanical properties of a commercial glass-ceramic LTCC tapes, and the metal paste order to be made mechanically robust multi-layer structure with the required electrical characteristics. Target calcining temperature was in the range of $850-940^{\circ} \mathrm{C}$ as the most suitable range for commercial LTCC metal pastes and tapes. These low temperature firing to be achieved while maintaining good dielectric and magnetic properties of the ceramic functional layers.

Behavior of compaction ceramics depending of additives on sintering obtained in [27] is compared with a commercial tape (Fig. 9). The curves show high compaction parameters (density $>95 \%$ of theoretical) at sintering temperatures of $900-940{ }^{\circ} \mathrm{C}$. Maximum compaction dielectric ceramics optimized approximately $200{ }^{\circ} \mathrm{C}$ higher than for the commercial LTCC tape in order to achieve near zero shrinkage.

During the firing of LTCC-tape shrink significantly - by more than $10 \%$. Shrinkage can cause significant and unmanageable change level of arching which must be compatible with some arching contact pads of

\section{REFERENCES}

1. Fang Chi Hsu, Heli Jantunen, Chi-Shiung Hsi, HsingI Hsiang, Min-Yu Yang, Chi-Wei Chang, Ceram. Int. 41, 12401 (2015)

2. H.I. Hsiang, W.C. Liao, Y.J. Wang, Y.F. Cheng, J. Eur. Ceram. Soc. 24, 2015 (2004).

3. J.H. Jean, C.R. Chang, J. Am. Ceram. Soc. 80, 3084 (1997).

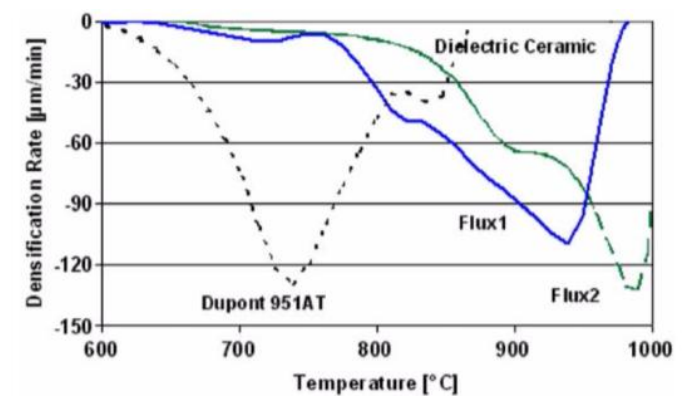

Fig. 9 - The indicators of compaction dielectric $(\mathrm{Ba}, \mathrm{Ca})(\mathrm{Zr}$, Ti) $\mathrm{O}_{3}$ ceramics with high $\mathrm{k}$ with various additives and commercial Dupont 951AT tape depending on temperature

semiconductor integrated circuits to which they are connected at a later stage. The most common sintering technology restricting lateral shrinkage (along the $\mathrm{X}$ and Y-direction) without pressure and, therefore, costeffective is lamination upper and rear tapes do not suffer from shrinkage and densification during sintering. After sintering these limiting layers are to be removed. For additional post-firing must be provided external connections. The technique developed by the authors [27], allows in a single step process to conduct a cofiring material with a high dielectric constant with commercial LTCC glass ceramic with a virtually zero shrinkage $(<1 \%)$ in the $\mathrm{X}$ - and Y-axis. This effect was achieved by adjusting the characteristics of the compaction dielectric ceramics. It was compacted below melting point $\mathrm{Ag}$ - and $\mathrm{Cu}$-electrode material, but above compaction temperature LTCC tape.

To achieve zero shrinkage and cracks LTCC composites further research is needed.

\section{CONCLUSION}

In the review examined the possibility of using LTCC-technology for obtaining hexaferrites as additives reaction glasses $\mathrm{Bi}_{2} \mathrm{O}_{3}-\mathrm{B}_{2} \mathrm{O}_{3}-\mathrm{SiO}_{2}-\mathrm{ZnO}$ (BBSZ) and $\mathrm{BaCu}\left(\mathrm{B}_{2} \mathrm{O}_{5}\right)$ (BCB) to reduce the sintering temperature.

It is shown that compatibility between hexaferrites with the addition BBSZ, BCB and silver paste, which is a key requirement in the manufacturing process LTCCcomponents.

Considered the possibility of co-sintering of ferrite and dielectric tape composites. It was established that for the realization of a defect-free LTCC- composite shrinkage ferrite and dielectric tape composites should tend to zero.

Work is executed in NUST "MISIS" with the financial support of the Ministry of Education of the Russian Federation within the grant agreement № 14.575.21.0030 on 27 June 2014 (RFMEFI57514X0030).

4. M. Oechsner, C. Hillman, F.F. Lange, J. Am. Ceram. Soc. 79, 1834 (1996).

5. J.Y. Hsu, H.C. Lin, H.D. Shen, IEEE T. Magn. 33, 3325 (1997).

6. J. Smith, H.P.J. Wijn, Philips Technical Library, Eindhoven, TheNetherlands (1959).

7. H.I. Hsiang, L.T. Mei, C.S. Hsi, W.C. Wu, J.H. Wu, 
F.S. Yen, Int. J. Appl. Ceram. Technol. 10, 160 (2013).

8. D. Autissier, A. Podembski, C. Jacquiod, J. Phys. IV. 07, 409 (1997).

9. S. Bierlich, J. Töpfer, IEEE T. Magn. 48, 1556 (2012).

10. R. Karmazin, O. Dernovsek, N. Ilkov, W. Wersing, A. Roosen, M. Hagymasi, J. Eur. Ceram. Soc. 25, 2029 (2005).

11. Daming Chen, Yingli Liu, Yuanxun Li, Wenguo Zhong, Huaiwu Zhang, J. Magn. Magn. Mater. 323, 2837 (2011).

12. Daming Chen, Yingli Liu, Yuanxun Li, Wenguo Zhong, Huaiwu Zhang, J. Magn. Magn. Mater. 324, 449 (2012).

13. Min-Han Kim, Jong-Bong Lim, Jae-Chul Kim, J. Am. Ceram. Soc. 89, 3124 (2006).

14. Hongguo Zhang, Longtu Li, Ji Zhou, Zhenxing Yue, Zhilun Gui, J. Am. Ceram. Soc. 84, 2889 (2001).

15. M. Drofenik, A. Znidarsic, D. Makovec, J. Am. Ceram. Soc. 81, 2841 (1998).

16. Jianguo Huang, Hanrui Zhuang, Wenlan Li, J. Magn. Magn. Mater. 256, 390 (2003).

17. Yaowen Li, Qin Wang, Hua Yang, Curr. Appl. Phys. 9, 1357 (2009).

18. Qinghui Yang, Huaiwu Zhang, Yingli Liu, Qiye Wen, $M a-$ ter. Lett. 63, 406 (2009).

19. Ying Liu, Michael G.B. Drewb, Jingping Wang, J. Magn. Magn. Mater. 322, 366 (2010).

20. Jihwan Park, Seung Hee Hong, Yongho Choa, Jongryoul Kim, phys. status solidi a 201, 1790 (2004).

21. Marcel Hagymasi, Andreas Roosen, Roman Karmazin, Oliver Dernovsek, Werner Haas, J. Eur. Ceram. Soc. 25, 2061 (2005).

22. M. Barker, R Draudt, Proceedings of the 2001 International Symposium on Microelectronics (IMAPS), 26 (2001).

23. K.R. Mikeska and D.T. Schaefer, U.S. Patent No. 5,474, 741 (1995)
24. O. Dernovsek, A. Naeini, G. Preu, W. Wersing, M. Eberstein, W.A. Schiller, J. Eur. Ceram. Soc. 21, 1693 (2001).

25. P.Z. Cai, D.J. Green, G.L. Messing, J. Am. Ceram. Soc. 80(8), 1929 (1997).

26. S.Y. Tzeng, J.H. Jean, J. Am. Ceram. Soc. 85(2), 335 (2002).

27. M. Matters-Kammerer, U. Mackens, K. Reimann, R. Pietig, D. Hennings, B. Schreinemacher, R. Mauczok, S. Gruhlke, C. Martiny, Microelectron. Reliability. 46, 134 (2006).

28. R.C. Lee, G-A. Lee, M. Megahed, Electr. Perform Electron Packaging 83, 6 (2003).

29. A. Mandou, L. Martens, IEEE T. Electromagnet Compat. 43(4), 549 (2001).

30. P.J. Stabile, A. Rosen, W.M. Janton, A. Gombar, M. Kolan, IEEE Microwave Symposium Digest, 448 (San Francisco, CA, USA, 29 May - 1 June, 1984).

31. K.M. Strohm, J.F. Luy, E. Kasper, J. Buechler, P. Russer, Mikrowellen-Magazin (West Germany) 14(8), 750 (1988)

32. M. Spirito, de Vreede LCN, L.K. Nanver, J.E. Mueller, J.N. Burghartz, Topical Meeting on Silicon Monolithic Integrated Circuits in RF Systems. Digest of Papers, 49 (Grainau, Germany, 9 - 11 April, 2003).

33. N.J. Pulsford, van Beek JTM, van Delden MHWM, A. Boogaard, R.F. Milsom, Microwave Symposium Digest, IEEE MTT-S, 41897 (1999).

34. Van Beek JTM, van Delden MHWM, van Dijken A, van Eerd P, van Grootel M., Proceedings 147 (2003).

35. D. Heo, A. Sutono, E. Chen, Y. Suh, J. Laskar, IEEE Microwave Wireless Components Lett. 11(6), 249 (2001).

36. E. Kim, Y-S. Lee, C-S, Yoo, W-S, Lee, J-C, Park, Eur. Microwave Conf. 1, 253 (2003). 